\title{
Change management in an academic library in the knowledge economy
}

\author{
Tanya Du Plessis ${ }^{1}$ and Tiyani Tyson Mabunda ${ }^{2}$ \\ tduplessis@uj.ac.za ORCID: orcid.org/0000-0002-8908-3601 \\ ttmabunda@uj.ac.za ORCID: orcid.org/0000-0003-2264-4280
}

\begin{abstract}
Received: 04 July 2016
Accepted: 08 August 2016

In the knowledge economy, knowledge is channelled in new ways which brings about changes to the structure and function of an organisation. Organisations such as academic libraries often introduce innovations in delivery of information services to clients which entail the use of information and communication technology. Current growth in technological applications is enabling academic libraries to change the way they deliver services to clients. Technological applications continuously redefine how academic library collections are used. This article investigates how change in terms of technology is managed in a decentralised academic library in a higher education institution of South Africa. The study was placed within a qualitative research paradigm. A case study design presented the research providing the opportunity to analyse the perception and experience of participants and ensured that real life events were investigated. Semi-structured individual interviews were used to collect data. The most significant finding of this study is the emphasis on the importance of change management in academic libraries and the need for effective communication in order to achieve low resistance to change from academic library staff.
\end{abstract}

Keywords: Change management, academic library, knowledge management, technological change

\section{Introduction}

Change as a result of technological innovations has an impact on customer needs, market dynamics and product competitors. Change is required when an organisation realises it is not operating at peak efficiency because its knowledge assets are not optimally managed in comparison with its competitors. The need to change signifies the transformation towards a knowledge economy, which first is evident in the growing perception of knowledge as one of an organisation's most critical resources (Liebowitz 1999). Knowledge has become a key economic resource and the dominant source of competitive advantage in the digital age (Drucker 2009: 190, Hirt \& Willmott 2014: 7). However, the movement towards the knowledge economy has not yet had global reach. Some of the reasons may be a lack of the presence of the following aspects of change management: establishing a sense of urgency; creating the guiding coalition; developing a vision and strategy; communicating the vision; empowering participants for action; generating short-term wins; consolidating gains and producing more change; and anchoring new approaches in the culture of an organisation (Kotter 2007). Any organisation aiming at participating in the knowledge economy is expected to put into practice these eight aspects of change management.

Change management is important because people in organisations require assistance in responding to changes that they face in the workplace (Austin \& Currie 2003: 230, Kotter 2012: 54). The top management of an organisation is responsible for developing strategies to assist people facing change. Change management aims at successful change efforts. An example of a successful change effort is when, after the introduction of a new technological application for improved access to academic information, the innovation is then used and becomes integrated into the information service offered by an academic library. Successful change efforts enable academic libraries to play their part in equipping current students and future graduates for meeting the challenges of the knowledge economy. Only academic libraries that succeed in this area are real role players in the knowledge society.

The knowledge society is giving rise to the emergent entrepreneurial university. Five facets reflect an entrepreneurial character: organised multi-disciplinary group research; creation of research knowledge bases with commercial potential; development of organisational mechanisms to move research out of the university as protected intellectual property; capacity to organise enterprises within the university; and integration of academic and business elements into new formats such as university-industry research centres (Carlson \& Kneale 2011: 168, Etzkowitz, Ranga \& Dzisah 2012: 159). Against this background, academic libraries worldwide are facing a time of change.

Academic libraries are expected to plan for change beginning with a situation analysis and diagnosis followed by developing an action plan that will guide the implementation of change. After implementation, the result then has to be evaluated. Libraries have to adopt change and become agile in their strategic decision-making in order to survive and

1. Tanya Du Plessis is an Associate Professor in the Department of Information and Knowledge Management, University of Johannesburg, South Africa

2. Tiyani Tyson Mabunda is a researcher in the Department of Information and Knowledge Management, University of Johannesburg, South Africa and a Team Leader III (Circulation), APK Campus Library. 
remain relevant in the changing environment of the knowledge economy. Botterhuis et al. (2009) and Barcan (2010) describe the knowledge economy as an unpredictable economy. Because of its unpredictability, library management are recommended to develop a change management strategy to guide the library into a favourable situation that promotes growth and relevance. Library management are expected to ensure that, when something new has been implemented, all departments combine their efforts of sharing knowledge so that the innovation can achieve better results.

To achieve better results, employees first need to understand the strategic direction of their organisation (Botterhuis et al. 2009, Barcan 2010). Employees with an understanding of the desired results contribute more towards the change process. Library management are expected at all times to communicate with employees and ensure that they understand the planned change process. Change often brings fear to employees; to combat fear, management's communication should be encouraging, open and honest so that employees may be inspired. Open communication builds employees' trust in those in leadership roles. Leadership and change management have been investigated extensively in the literature (Stripeikis \& Zukauskas 2005, Ntsunguzi 2007, Kotter \& Schlesinger 2008, Sutanto et al. 2008, Bold 2011, Gans 2011, Nakhoda, Alidousti \& Fadaie 2011). The research gap filled by the current study is the necessity of change management within a decentralised academic library that has gone through a merger and is now aiming to transform towards the knowledge economy.

In order to analyse the role of change management for the academic library in the knowledge economy, given the above context, this study focused on one of South Africa's recently-merged universities with an academic library consisting of four geographically-dispersed library centres. The article begins with an overview of the basic components of change management, the phases of the change management process in the knowledge economy, and some of the key enablers and barriers to change management. The research objective was to investigate the need for change management in academic libraries as role players in the knowledge economy. The research methodology section gives a motivation of the case study research design. The main research question was: How is change managed in a merged, decentralised academic library environment?

\section{Change management in academic libraries in the knowledge economy}

The purpose of this literature review is to establish a theoretical framework which will give structure to a study of change management of a decentralised academic library in South Africa aiming to transform towards the knowledge economy.

\subsection{Basic components of change management}

Change management helps organisations identify barriers to change and combat resistance to change; it also develops a strategy to overcome barriers and resistance to change (Sutanto et al. 2008). Stripeikis and Zukauskas (2005: 333) point out five of the most basic components of change management, namely defining set goals, establishing what will not be changed, getting employees into the process, creating a plan for change, and communicating with employees. These components are illustrated in Figure 1.

Figure 1 Components of successful change management (Stripeikis \& Zukauskas 2005: 333)

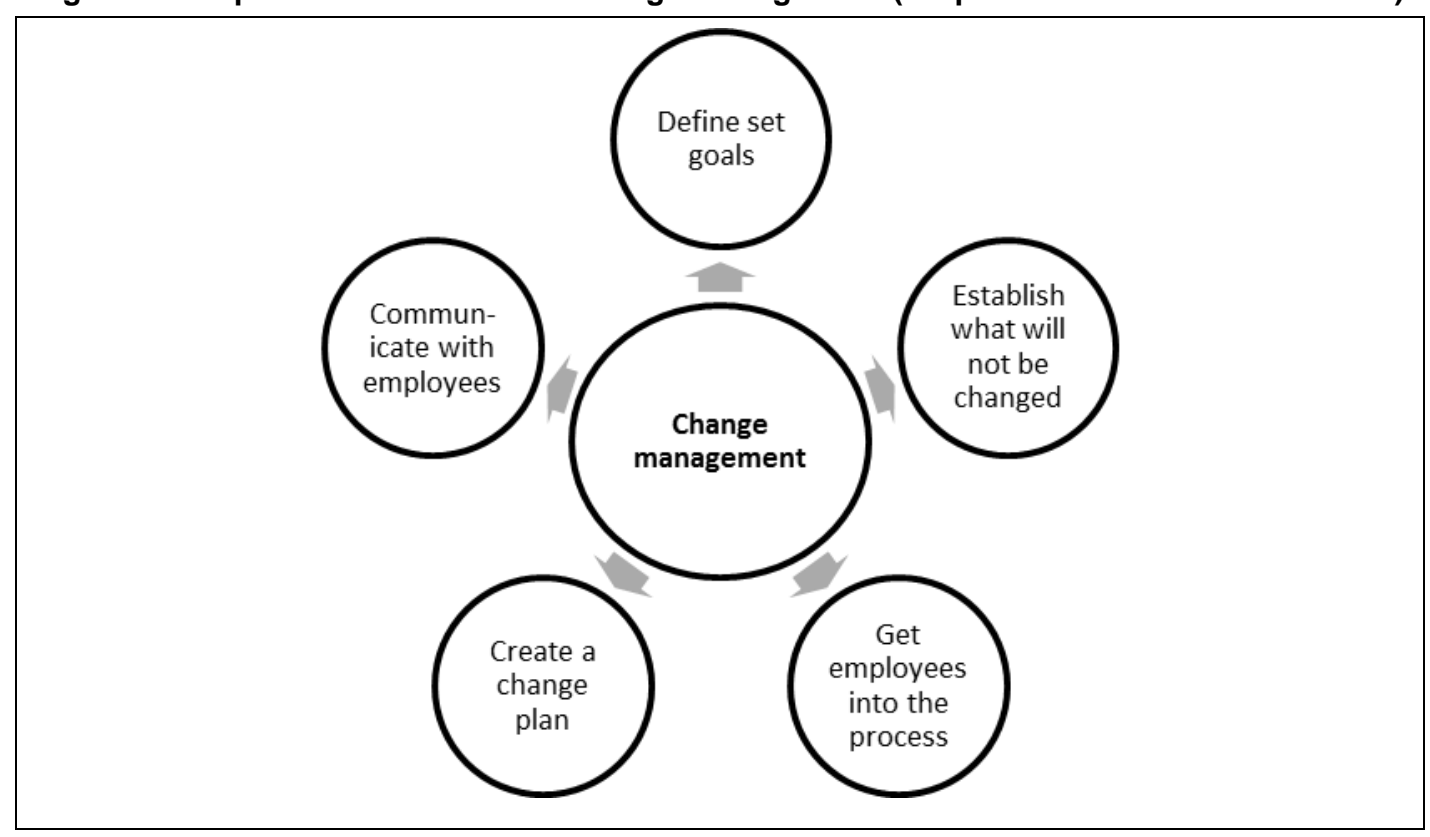

Successful change management relies on a structured approach aimed at ensuring that the transition from the current state to a desired state is achieved (Ntsunguzi 2007: 14, Bold 2011: 12). Essentially, the objective of change management is the empowerment of individuals which, in turn, will lead to the organisation transitioning to the desired future. 


\subsection{Phases of change management in the knowledge economy}

In the knowledge economy, the flow of knowledge is channelled into new sources of technological innovation that bring along changes in the structure and function of an organisation (Etzkowitz \& Leydesdorff 1997). Managing change is an important process to be undertaken because it enables the organisation to correct its mistakes during the process of change and enables it to reach new solutions and set new goals (Newman 2012: 67). Kotter's change phase model is one of the models often used to transform an organisation from its traditional state to the desired state (Kotter \& Cohen 2002, Mento, Jones \& Dirndorfer 2002, Kotter 2007). This model has eight key phases, namely:

- Phase 1 - Establishing a sense of urgency: Most people do not like change to take place; people find change difficult. This stage aims to ensure that people understand that change needs to happen; that something should be done. This phase helps to reduce the number of people who will not accept change (Kotter 2007).

- Phase 2 - Creating the guiding team: The right people have to be selected to manage change. People should be grouped together as a team powerful enough to lead change. Successful change happens when it is led by a group of leaders with knowledge and experience on that particular change initiative (Kotter 2013).

- Phase 3 - Developing a vision: A shared vision gives people direction and motivates them in supporting the vision. When the vision has been developed, it will be easy for the guiding team to direct the change efforts. At this stage, strategies for achieving the vision are also developed as people begin to share a vision and make it their reality (Kotter 2007).

- Phase 4 - Communicating the change vision: Appropriate methods such as face-to-face discussions, emails, intranet posts, portals and social media applications should be used to give relevant change vision information and obtain employee buy-in (Kotter \& Schlesinger 2008).

- Phase 5 - Empowering employees: To act on the vision, employees have to be empowered: obstacles that will limit them from performing well on the change vision need to be removed. Obstacles could be the lack of skills or human resources or the changing of systems or structures that undermine the change vision (Kotter 2007).

- Phase 6 - Creating and celebrating short-term wins: Motivation is key to successful change management; those employees who are performing well should be rewarded because they are contributing towards making the change vision successful and improving performance in the organisation (Kotter 2007).

- Phase 7 - Broadening the change: Change taking place in a particular section of an organisation tends also to affect other sections of the organisation. Change has to be successfully broadened to all interrelated sections. At this stage, it is important to eliminate unnecessary work like the duplication of processes (Kotter 2007).

- Phase 8 - Embedding the change in the culture of the organisation: Organisational culture consists of the behaviours and norms of people in the workplace; its organisational values. When change takes place, new values may surface together with behavioural norms and shared vision that accommodate the change (Kotter 2007).

It is important that organisations follow a phased approach to introducing change so that the barriers to change can be effectively overcome. Barriers can be prevented when organisations know the enablers of change.

\subsection{Key enablers and barriers to change}

In order for organisations to implement change in the knowledge economy successfully, they need to pay full attention to the enablers of change. Some key enablers and barriers to change emerge from the literature review (Stripeikis \& Zukauskas 2005, Ntsunguzi 2007, Kotter \& Schlesinger 2008, Sutanto et al. 2008, Bold 2011, Gans 2011, Nakhoda, Alidousti \& Fadaie 2011). These enablers and barriers are listed in Table 1. Communication and strong leadership are required so that factors can become enablers of change instead of barriers to it.

Table 1 Key enablers and barriers to change

\begin{tabular}{ll}
\hline Enablers to change & Barriers to change \\
\hline Educated cross-functional teams with high performers and the right skills & Resistance to change \\
Effective communication & Lack of communication \\
Good project management & Ineffective project management \\
Continuous employee involvement & Focusing on change that is not sustainable \\
Top management commitment and leadership & Lack of strong leadership and low top management involvement \\
Aligning change within the culture of the organisation & An approach to change that is not systemic \\
\hline
\end{tabular}

Wood, Miller and Knapp (2007), Oakland and Tanner (2007), and Watson (2010), suggest that, before organisations such as academic libraries undertake any change efforts, it is sensible first to understand their specific role in the knowledge economy. 


\subsection{The role of libraries in the knowledge economy}

In the knowledge economy, libraries are seen as reservoirs for knowledge by making sources of high-quality information available to clients. Once people acquire knowledge, they are better positioned to make decisions that are likely to improve their lives. Active decision-makers who apply their knowledge in innovative ways are the people participating in the development of the economy; they often contribute as entrepreneurs and by improving the lives of others (Kargbo 2011, Etzkowitz, Ranga \& Dzisah 2012). Libraries present learning environments for many of these people in which they acquire the skill of effectively searching, evaluating and using reliable information. Information literacy training enables people to learn how to choose only high-quality information sources and to use information ethically and wisely. In the knowledge economy, it is crucial for people to obtain advanced information literacy skills (Clarke 2001, Tuominen, Savolainen \& Talja 2005, Hancock \& Spicer 2011).

The needs of people visiting and using the services of academic libraries in the knowledge economy differ from past needs. One reason for the difference is the requirement of university curricula for them to work and study in groups (Sidorko \& Yang 2009). Nowadays, academic libraries have become a work and social space for users of social media applications as part of their learning experience. Technological developments are playing a positive role in delivering content for learning. These developments have transformed libraries into "knowledge commons for collective learning" (Duderstadt 2009). More recently, cloud computing is playing a role in academic libraries by allowing services such as group training and those of sharing and accessing useful information, not only from other libraries but also other essential partners in the knowledge economy. Excellent levels of client service are achieved with the help of, for example, research and commercialisation units with sensors in laboratories; cloud computing and big data; and a combination of various mobile applications with extended access to other resources and tools (Scale 2010, Hirt \& Willmott 2014, Caetano et al. 2016). Thus, libraries have an important role to play in the knowledge economy. In order to remain relevant, they have to manage change effectively and on a continuous basis.

\subsection{Change management in academic libraries}

The increase in the use of information and communication technologies (ICTs) in education characterises the change in academic libraries (Siddiqui 2003, Ahmed 2011, Mottaghi-Far 2012). The development of ICTs over the past few years has enabled libraries to change the way they function. Access to information, circulation, acquisition and cataloguing are some of the typical library functions and departments that have been affected by ICT developments. Change takes place in all library departments, in all their activities. Services have shifted to specialise more in e-service and e-products because the majority of library clients have access to devices such as computers, laptops, iPads, smartphones and tablets to gain access to information (Konings \& Dekker 2005, Wood, Miller \& Knapp 2007, Nakhoda, Alidousti \& Fadaie 2011, Mottaghi-Far 2012, Ashill, Casagranda \& Stevens 2016).

The focus of this study is on change associated with using new technologies and how this change is managed by library management together with its employees. All academic library staff are expected to know that change brings new experience and growth. When change is about to happen, communication and collaboration are essential in achieving a positive change effort. With the move towards the knowledge economy, change management becomes a priority. Academic libraries have to monitor their environment continuously so that they do not become marginalised. They continuously have to change in order to be competitive and successful in delivering relevant services to their clients. Change should be reflected in library policies, collections, budgeting, staffing, and service delivery mechanisms. Resistance to change is not unusual and therefore change should be carefully managed.

\section{Research methodology}

This study investigated change management at an academic library to gain greater understanding of how change is managed in a merged, decentralised academic library environment. In order to gain insight from the perspectives of individuals, this study followed a qualitative approach which consisted of semi-structured interviews with academic library employees at management and staff levels. The semi-structured interviews offered richer data and the data collection method allowed the researcher to be flexible and extend and formalise conversations. Although the process of collecting data was time-intensive, individual interviews did not exceed a one-hour time limit in order to ensure participants' maximum participation while still respecting their work schedules.

Participants provided answers to specific questions which, through analysis of the responses of participants about situations in and of the library environment, help in constructing the reality, as Yin (2012: 12) has explained. An audio recording device was used to record conversations with participants in order to ensure research integrity by creating and preserving a record of primary data. Consent was obtained from participants. Participants were duly informed of the research objective. Their participation was voluntary and anonymous. Kumar (2005: 164) and Botha (2007: 41) suggested a sampling strategy that enables researchers to select certain units from the target group in order to reduce the number of representatives of the population. This study applied purposive sampling in order to select participants capable of providing data about how change is managed in a decentralised academic library.

Primary data was collected from the staff of a decentralised academic library, representing five groups as illustrated in Figure 2. In total, twenty-one participants were interviewed. 
Figure 2 Sampling groups

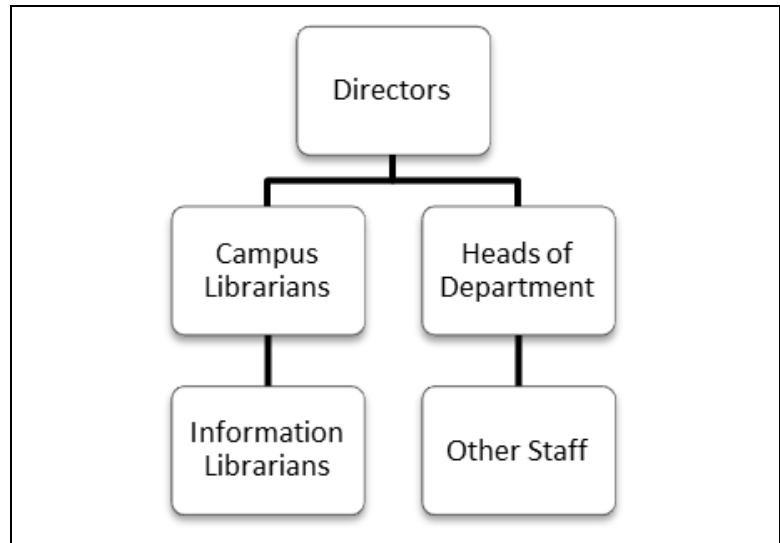

\section{Research findings and discussion}

The frequency distribution of participants by position level is presented in Table 2. Firstly, the study collected data regarding change management from participants at all staff levels. Secondly, although the study was not based on the generation theory which deals with the theoretical treatment of generations as a sociological phenomenon, it was also deemed necessary to ensure representation from different generations of staff. The majority of the participants were Information Librarians, followed by the Heads of Department.

Table 2 Frequency distribution of participants by position level

\begin{tabular}{lcc}
\hline Position level & Frequency & Percentage \\
\hline Director & 2 & $9.5 \%$ \\
Campus Librarian & 3 & $14.3 \%$ \\
Information Librarian & 8 & $38.1 \%$ \\
Head of Department & 7 & $33.3 \%$ \\
Other Staff & 1 & $4.8 \%$ \\
TOTAL & $\mathbf{2 1}$ & $\mathbf{1 0 0} \%$ \\
\hline
\end{tabular}

Most participants were either in their forties or represented the 56+ age group. The age groups of participants could potentially give a deeper understanding of whether resistance to change can be associated with a specific age group or groups, generation or generations. However, the main research question was not to make deductions based on the generation theory.

Table 3 Frequency distribution of participants by age group

\begin{tabular}{lcc}
\hline Age group & Frequency & Percentage \\
\hline $\mathbf{2 0 - 2 9}$ years & 2 & $9.5 \%$ \\
$\mathbf{3 0 - 3 9}$ years & 4 & $19 \%$ \\
$\mathbf{4 0 - 4 9}$ years & 6 & $28.6 \%$ \\
$\mathbf{5 0 - 5 5}$ years & 3 & $14.3 \%$ \\
$\mathbf{5 6 +}$ years & 6 & $28.6 \%$ \\
TOTAL & $\mathbf{2 1}$ & $\mathbf{1 0 0} \%$ \\
\hline
\end{tabular}

Table 2 and Table 3 above indicate the proportional distribution of participants as a result of this study's purposive sampling strategy. The findings from the interviews give a deeper understanding of how change in terms of technology is managed in a merged, decentralised academic library environment.

Participants shared a common perception that there are two 'types' of employees - those who embrace technological change and those opposing change. From the interview findings, it was evident that participants of above 55 years of age were less eager to embrace new technology than the younger participants. All participants said that any employee could potentially embrace change, regardless of age. Some participants felt that certain employees did not like change due to generational challenges. The younger generations were more motivated to adapt to change and were more frequently the initiators in the uptake of new technology than was the older generations. It was perceived by some participants that their colleagues were sometimes intimidated by new technology, that it complicated their work, and that it was possible that they would lose their jobs if they were not using new technology. 
Even though questions related specifically to IT systems change, respondents included responses about mergerrelated change. It became clear that merger, management, and systems change became one issue in the experience of the interviewees. The majority of the participants reported that they had experienced previous changes to library management which meant that they had had to deal with different management styles and new systems. These participants felt as if they had been taken out of a working environment to which they had become accustomed over a period of time. This perception was not purely related to technological change; instead it was merger-related leadership change which in some instances led to system change. Some participants experienced change in library strategy, vision, mission, values, policies, procedures, how employees work, and in work ethic. Table 4 shows the way in which participants experienced change either in a positive or negative manner.

Table 4 The positive and negative experience of change

\begin{tabular}{|c|c|}
\hline ange & erience of change \\
\hline $\begin{array}{l}\text { - The movement of people from past state to the current defined } \\
\text { - The movemproved the level of staff commitment } \\
\text { - } \quad \text { state has clarified job roles } \\
\text { In life there should be change, people just need to adjust and } \\
\text { experience change as positive } \\
\text { - Change is a good thing and it must have a good purpose and } \\
\text { good outcome } \\
\text { Employees should realise that they need to adjust to new } \\
\text { management styles because change is one of life's realities } \\
\text { - Change is positive, we are working hard because we need to } \\
\text { perform well } \\
\text { Change to new leadership brought more understanding and new } \\
\text { strategies }\end{array}$ & $\begin{array}{l}\text { - } \quad \text { Change affects the comfort of the working environment } \\
\text { At times, it was painful to be taken out of a comfort zone } \\
\text { and having to go through the various stages of the change } \\
\text { process } \\
\text { - There is a lack of communication in advance which made it } \\
\text { hard to adapt to change } \\
\text { - Change made one think negatively because it created more } \\
\text { stress and tension } \\
\text { - The workload was doubled } \\
\text { - The effect of change is perceived at an emotional level } \\
\text { - The way change was introduced was not good } \\
\quad \text { authoritarian much work and change is experienced as } \\
\text { - Management sometimes fails to consider staff opinion }\end{array}$ \\
\hline
\end{tabular}

The findings presented in Table 4 are worth noting because they portray the participants' experiences of change in general. All participants affirmed that change management is important when introducing something new to the library, but they offered different reasons for their opinion. The majority said that people do not all experience change in the same way and that is why change should be managed. Change should be managed in order to get everyone 'on board' by explaining and communicating to them what the purpose of change is so that they may trust in and be aware of what is happening.

An effective communication method mentioned by most participants included strategy meetings attended by team leaders, managers and directors. During these meetings, change visions and progress of the current change were explained and discussed. Another effective method was when library management held monthly meetings with each department where they communicated information about their vision for the library to all attending staff. It was pointed out by one participant that, although library management was communicating, management did not always invite or welcome staff's opinion or advice regarding their change plan. Besides these meetings, management also used a listserv to communicate with every library staff member; it was up to staff to access the listserv.

The participants who felt that the communication at the library was not effective said that they had to "ask in order to know", and added that communication was not received through good channels but rather through "the grapevine". These participants felt that, since they were not updated about the changes that were taking place in the library, the library management did not communicate in a timely fashion. One participant responded that more information was communicated when there was a campus visit to be expected from university management. From the findings, it seems that the library management do communicate, but that their communication is not always perceived as effective.

Some of the participants specified that library management indicated to staff the direction in which they were heading, however they believed that line managers were not communicating well to staff. One of the participants mentioned that top management insisted that all managers and heads of department communicate all information to staff directly after their meetings. From these findings, this study shows that attention should be given to communication at all managerial levels in order to have good change management.

Specific attention was given in the interviews to employees' motivation to adapt to technological change. Surfacing from the interviews were five categories of reason for being motivated to adapt to change. These categories were: when the change is perceived as having great benefit; when support was received from library management; being selfmotivated by the use of new technologies; motivated by practising intensively the use of new technology; and being motivated through training and workshops.

The findings presented in Figure 3 show that the major reasons why participants said they adapted to change was because of self-motivation and when the new technology showed great benefit to the service they delivered. Participants also indicated that training and workshops motivated them to adapt to new technologies because they were able to understand how a particular new system worked. It became easy for them to perform their duties after they have been trained on a particular system before it was implemented so that they could confidently assist library clients.

The findings correlate with the literature in which it was found that library management must explain the importance of new technology to staff in order to promote buy-in and support staff in the process of change, for example, in using a new system. However, this study indicates that, although participants do consider support from library management as an 
important motivation, it was second to knowing what the benefit of change entails. Benefit of change supersedes challenges; and even though participants felt initial resistance to new technology because of the challenges it posed, they felt motivated as soon as intensive practice showed positive results. This emphasises the importance of staff familiarising themselves with new technology and trying to use it.

Figure 3 Motivation to adapt to change

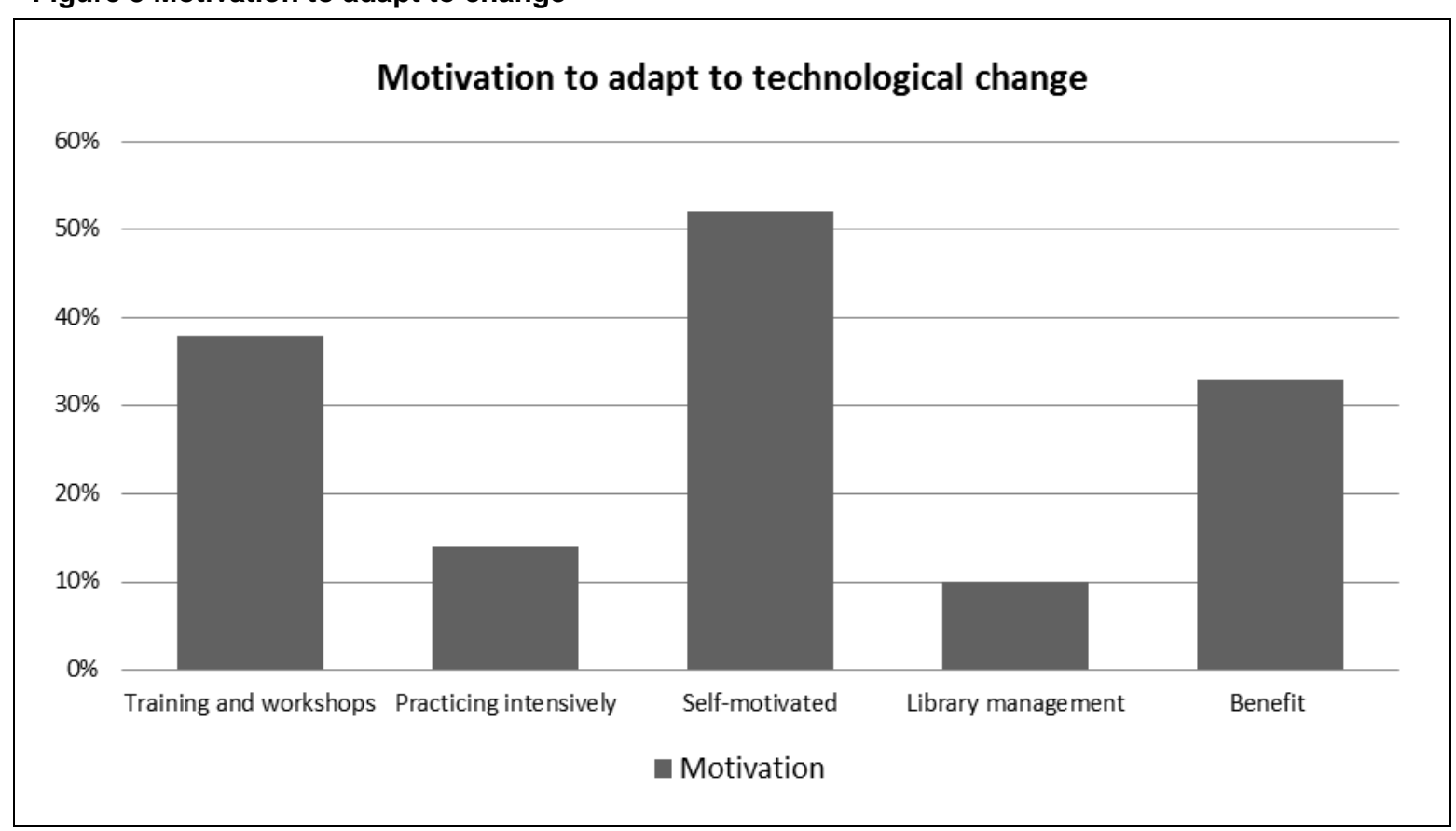

The perceived benefits and challenges the participants associated with technological change became evident from the data collected during interviews. The majority of participants felt that technological change had benefited them by improving their level of service in terms of time efficiency and professional service offering. For example, a new system for the online ordering of books has greatly improved the existing online ordering system from a user perspective. Another major benefit is accessibility of information, especially in the case of remote access. Some of the participants felt that technological change was making their lives easier because, through the use of social media, they were serving people with no time limitations. Embedded service offering - for example, using mobile applications to offer information services via the preferred platforms of library clients - was mentioned by some participants, but only two of the participants actually offered embedded services. Two participants felt that clients were attracted by the wireless internet access available in the library. Though this was generally perceived as technological progression, one participant raised the concern of maintaining the library's character as an academic information service provider.

In terms of the challenges associated with technological change, frustration was expressed at the high frequency of technological change. This finding is also reflected in the literature. Mittal (2012) highlights the importance of training as a way of reducing employees' frustration due to frequent change. Participants were of the opinion that effective communication was the most effective solution to overcoming resistance to change.

It should be noted that the discussion above of the research findings is based on data collected as part of a crosssectional study. The study was limited to a decentralised academic library that has gone through a merger and therefore the results can only be generalised to a similar setting and not universally to universities. Also, the empirical component of the study mostly focused on what is considered to be one of the most important characteristics of the knowledge economy, namely, relying more on new technologies to enhance service delivery. Other characteristics of the knowledge economy were discovered in the literature review but were not covered in this study. These limitations have to be noted and read along with the conclusion that follows.

\section{Conclusion}

Change management is aimed at providing individuals in an organisation with the support and development they require in order to accept, understand and benefit from change, as well as efficiently manage the challenges associated with change. In conclusion, the research findings correspond with Kotter's (2007) theory that effective communication is crucial to increase individual understanding and commitment to change, reducing resistance and confusion, and preparing people for positive and negative change outcomes. This study concurs with other studies emphasising the importance of communication: library management is expected to communicate the change vision. However, it was found that, although library management encouraged communication, sometimes middle management tended to be less successful in communicating effectively the change vision to employees.

Other findings of significance are that all library staff generally had a common motivation for the adoption of new technology, namely, they wanted the library to be known as an academic information service provider that delivers 
outstanding service. Except for being self-motivated, other factors such as training opportunities, workshops, intensive practice, and the benefit of change also motivated library staff to adapt to change. Training increases the motivated use of new technologies which might potentially lead to increased productivity. Follow-up training must be encouraged in consideration of those employees who are slower in adapting to technological change.

In essence, library management must ensure that a good communication plan is prepared and followed. All employees affected by change must receive regular feedback about the status of change, its effect and accomplishments. Communication creates confidence in the change process and also fosters mutual trust. Communication lessens the possibility of incorrect information reaching employees through 'the grapevine'. An aspect that was not mentioned by research participants which requires further investigation is that library clients must be included in the communication plan so that they can know what change is taking place in the library, why it is happening, and the value of change - in other words, what the benefit will be for them. In closing: the benefits of change surpass its challenges.

\section{References}

Ahmed, A.S. 2011. Multimedia technologies in university libraries: opportunities and tasks. European Journal of Scientific Research, 59(2): 216-218.

Ashill, N.J., Casagranda, L. and Stevens, P.M. 2016. Competitive advantage using the internet: evidence from New Zealand primary sector industries. [Online]. https://www.researchgate.net/publication/228635432_Creating_Competitive_Advantage_using_the_Internet_Evidenc e_from_New_Zealand_Primary_Sector_Industries (30 April 2016).

Austin, J. and Currie, B. 2003. Changing organisations for a knowledge economy: the theory and practice of change management. Journal of Facilities Management, 2(3): 229-243.

Barcan, L.M. 2010. Change management of organization in the knowledge economy. Annals of University of Craiova Economic Sciences Series, 3(38): 1-6.

Bold, E. 2011. Instruments and techniques used in the design and implementation of change management. Journal of Advanced Research in Management, 1(3): 5-13.

Botha, G.J. 2007. Organisational change towards building a learning organisation. PhD thesis. University of Johannesburg. [Online]. https://ujdigispace.uj.ac.za/ (28 June 2014).

Botterhuis, L., Van der Duin, P., De Ruijter, P.A. and Van Wijck, P. 2009. Monitoring the future: building an early warning system for the Dutch Ministry of Justice. Futures, 42(5): 1-12.

Caetano, A., Antunes, G., Pombinho, J., Bakhshandeh, M., Granjo, J., Borbinha, J., and Da Silva, M.M. 2016. Representation and analysis of enterprise models with semantic techniques: an application to ArchiMate, e3value and business model canvas. Knowledge and Information Systems, March: 1-32.

Carlson, J. and Kneale, R. 2011. Embedded librarianship in the research context: navigating new waters. College \& Research Libraries News, 72(3): 167-170.

Clarke, T. 2001. Knowledge management: the knowledge economy. Education \& Training, 43(4/5): 189-196.

Drucker, P.F. 2009. Managing in a time of great change. Boston, MA: Harvard Business Press.

Duderstadt, J.J. 2009. Possible futures for the research library in the $21^{\text {st }}$ Century. Journal of Library Administration, 49(3): 217-225.

Etzkowitz, H. and Leydesdorff, L. 1997. Universities and the global knowledge economy: a triple-helix of universityindustry-government relations. London: Printer.

Etzkowitz, H., Ranga, M. and Dzisah, J. 2012. Industrial to knowledge society and the transition from Novum Trivium: whither the university? Social Science Information, 51(2): 143-164.

Gans, K. 2011. Should you change your thinking about change management? Strategic Finance, 93(4): 48-50.

Hancock, P. and Spicer, A. 2011. Academic architecture and the constitution of the new model worker. Culture and Organization, 17(2): 91-105.

Hirt, M. and Willmott, P. 2014. Strategic principles for competing in the digital age. McKinsey Quarterly, May: 1-13.

Kargbo, J.A. 2011. Public library services in the knowledge economy: the Sierra Leone experience. Public Library Quarterly, 30(1): 62-75.

Konings, K. and Dekker, R. 2005. Strategy and change management in DELFT University of Technology Library. New Review of Information Networking, 11(1): 109-121.

Kotter, J.P. 2007. Leading change. Harvard Business Review, 85(1): 96-103.

Kotter, J.P. 2012. How the most innovative companies capitalize on today's rapid-fire strategic challenges and still make their numbers; accelerate! Harvard Business Review, 90(11): 44-58.

Kotter, J.P. 2013. Change leadership. Leadership excellence, 30(1): 6.

Kotter, J.P. and Cohen, D. 2002. The heart of change: real life stories of how people change their organizations. Boston: Harvard Business School Publishing.

Kotter, J.P. and Schlesinger, L.A. 2008. Choosing strategies for change. Harvard Business Review, 86(7): 130-139.

Kumar, R. 2005. Research methodology: a step-by-step guide for beginners. London: SAGE.

Liebowitz, J. 1999. Knowledge management handbook. Boca Raton, FL: CRC Press.

Mento, A.J., Jones, R.M. and Dirndorfer, W. 2002. A change management process: grounded in both theory and practice. Journal of Change Management, 3(1): 45-59.

Mittal, S. 2012. Managing employee resistance to change: a comparative study of Indian organisations and MNCs in Delhi-NCR Region. International Refereed Research Journal, 3(4): 64-71. 
Mottaghi-Far, H. 2012. Employing a knowledge management process in academic and research libraries: a productive thinking one. Interdisciplinary Journal of Contemporary Research in Business, 3(9): 1468-1479.

Nakhoda, M., Alidousti, S. and Fadaie, G.R. 2011. Selecting an appropriate change management model for Iranian Academic Libraries using MADM Methods. Libri: International Journal of Libraries \& Information Services, 61(3): 190204.

Newman, J. 2012. An organisational change management framework for sustainability. Greener Management International, 57: 65-75.

Ntsunguzi, N. 2007. Change management in the implementation of shared services. PhD thesis. University of Johannesburg. [Online]. https://ujdigispace.uj.ac.za/ ( 28 June 2014).

Oakland, J.S. and Tanner, S. 2007. Successful change management. Total Quality Management \& Business Excellence, 18(1/2): 1-19.

Scale, M.E. 2010. Assessing the impact of cloud computing and web collaboration on the work of distance library services. Journal of Library Administration, 50(7/8): 933-950.

Siddiqui, M.A. 2003. Management for change in acquisitions in academic libraries. The Electronic Library, 21(4): $352-357$.

Sidorko, P.E. and Yang, T.T. 2009. Refocusing for the future: meeting user expectations in a digital age. Library Management, 30(1/2): 6-24.

Stripeikis, O. and Zukauskas, P. 2005. Change management: a key factor of the learning organisation in knowledgebased economy. Knowledge-based Economy: Management of Creation \& Development, 323-337.

Sutanto, J., Kankanhalli, A., Tay, J., Raman, K.S. and Tan, B.C.Y. 2008. Change management in interorganizational systems for the public. Journal of Management Information Systems, 25(3): 133-175.

Tuominen, K., Savolainen, R. and Talja, S. 2005. Information literacy as a sociotechnical practice. The Library Quarterly, 75(3): 329-345.

Watson, L. 2010. The future of the library as a place of learning: a personal perspective. New Review of Academic Librarianship, 16(1): 45-56.

Wood, E.J., Miller, R. and Knapp, A. 2007. Beyond survival: managing academic libraries in transition. London: Libraries Unlimited.

Yin, R.K. 2012. Applications of case study research. London: SAGE. 